Pesq. Vet. Bras. 29(1):33-40, janeiro 2009

\title{
Ocorrência e fatores de risco para Chlamydophila abortus em ovinos e caprinos no estado de Pernambuco ${ }^{1}$
}

\author{
Márcia de Figueiredo Pereira ${ }^{2 *}$, Rodolfo de Moraes Peixoto ${ }^{3}$, Rosa Maria \\ Piatti $^{4}$, Elizabeth Sampaio de Medeiros ${ }^{3}$, lagmar Oliveira da Mota ${ }^{3}$, Sérgio \\ Santos de Azevedo 5 e Rinaldo Aparecido Mota ${ }^{2}$
}

\begin{abstract}
Pereira M.F., Peixoto R.M., Piatti R.M., Medeiros E.S., Mota I.O., Azevedo S.S. \& Mota R.A. 2009. [Occurrence and risk factors for Chlamydophila abortus infection in sheep and goats in Pernambuco.] Ocorrência e fatores de risco para Chlamydophila abortus em ovinos e caprinos no estado de Pernambuco. Pesquisa Veterinária Brasileira 29(1):33-40. Departamento de Medicina Veterinária, Universidade Federal Rural de Pernambuco, Rua Dom Manoel de Medeiros s/n, Recife, PE 52.171900, Brazil. E-mail: marcia.pereira@dmv.ufrpe.br

The study aimed to identify risk factors associated with Chlamydophila abortus infection in sheep and goats from the Litoral/Zona da Mata and Agreste region of Pernambuco state, Brazil. Serum samples $(n=290)$ were analyzed to detect Chlamydophila spp. antibodies in 12 farms. Questionnaires were applied to identify risk factors. Frequency of serum-reactive animals were $10.3 \%$ (12.0\% in ewes and $8.1 \%$ in goats) and $1 / 12(91.6 \%)$ infection focuses were identified. This is the first report on anti-Chlamydophhila abortus antibodies in goats and sheep in Pernambuco and Brazil, respectively. Risk factors associated with goat infection were breed $(O R=9.10)$ and management $(O R=6.41)$. No significant associations in any of the analyzed factors were found for sheep. In summary, Chlamydophila sp. infection is disseminated in sheep and goat herds in the region. Control measures should be established, focusing primarily risk factor identified in this study, to reduce the possibility of infection by the agent.
\end{abstract}

INDEX TERMS: Complement Fixation Test, Chlamydophila abortus, risk factors.

RESUMO.- Objetivou-se com este estudo identificar os fatores de risco associados à infecção por Chlamydophila abortus em caprinos e ovinos nas regiões do Litoral/Zona da Mata e Agreste do Estado de Pernambuco. Foram coIhidas 290 amostras de soros para pesquisa de anticorpos contra clamídia em 12 propriedades. Para identificar

\footnotetext{
${ }^{1}$ Recebido em 12 de novembro de 2007.

Aceito para publicação em 5 de agosto de 2008.

2 Departamento de Medicina Veterinária, Universidade Federal Rural de Pernambuco (UFRPE), Rua Dom Manoel de Medeiros s/n, Dois Irmãos, Recife, PE 52171-900, Brasil. *Autor para correspondência: marcia.vet-ufrpe@ hotmail.com

${ }^{3}$ Programa de Pós-Graduação em Ciência Veterinária, UFRPE, Recife, PE.

${ }^{4}$ Instituto Biológico de São Paulo, Rua Conselheiro Rodrigues Alves 1252, Vila Clementina, São Paulo, SP 04014-002, Brasil.

${ }^{5}$ Unidade Acadêmica de Medicina Veterinária, Centro de Saúde e Tecnologia Rural (CSTR), Universidade Federal de Campina Grande (UFCG), Patos, PB 58700-000, Brasil.
}

os fatores de risco foram aplicados questionários junto aos proprietários. A freqüência de animais soro-reagentes nos rebanhos estudados foi de $10,3 \%$, sendo $12,0 \%$ para caprinos e $8,1 \%$ para ovinos, identificando-se $11 / 12$ $(91,6 \%)$ focos da infecção. Registra-se a primeira ocorrência de anticorpos anti- $C$. abortus em caprinos no estado de Pernambuco e em ovinos no Brasil. Os fatores de risco associados à infecção em caprinos foram a raça $(\mathrm{OR}=9,10)$ e o manejo intensivo $(\mathrm{OR}=6,41)$ e para ovinos não foram encontradas associações significativas para nenhum fator analisado. Concluiu-se que a infecção por Chlamydophila sp. encontra-se disseminada em criações de caprinos e ovinos da Zona da Mata e Agreste do Estado de Pernambuco. Medidas de controle devem ser implantadas nos criatórios estudados, enfocando principalmente os fatores de risco identificados neste estudo para reduzir a possibilidade de infecção por este agente.

TERMOS PARA INDEXAÇÃO: Reação de Fixação de Complemento, Chlamydophila abortus, fatores de risco. 


\section{INTRODUÇÃO}

A clamidofilose é uma infecção bacteriana responsável por distúrbios reprodutivos em várias espécies. Em caprinos e ovinos, a Chlamydophila abortus é um dos agentes mais freqüentemente isolados de ovelhas e cabras que abortaram, em vários países do mundo (Rodolakis 2001). Além dos graves prejuízos econômicos atribuídos à infecção por este agente (Nieuwhof \& Bishop 2005), destaca-se, ainda o seu potencial zoonótico (Papp \& Shewen 1997).

O diagnóstico da infecção no rebanho é feito pela sorologia, utilizando-se o método da Reação de Fixação do Complemento (RFC), segundo recomendação da Organização Mundial de Saúde Animal (OIE 2000).

No Brasil, ainda são poucos os estudos sobre a clamidofilose em ruminantes. O primeiro relato foi feito por Freitas \& Machado (1988), que isolaram a clamídia de órgãos de búfalos abatidos para consumo em Belém, no Estado do Pará. Igayara-Souza et al. (2004) realizaram estudos de prevalência em bovinos no Estado de São Paulo e encontraram $5,3 \%$ de animais positivos. Piatti et al. (2006) relataram uma prevalência de $12,0 \%$ para caprinos, procedentes dos Estados de São Paulo, Mato Grosso, Minas Gerais e Bahia. Os ovinos apresentaram resultado negativo. Romijn \& Liberal (1990) também isolaram a clamídia, por cultivo celular, de pulmão e traquéia de bezerros necropsiados no Rio de Janeiro, e Gomes et al. (2001) isolaram o microorganismo de fluido seminal de touros com vesiculite.

Considerando-se a escassez de informações sobre a clamidofilose no Brasil, este trabalho teve como objetivo determinar a ocorrência da infecção por $C$. abortus em caprinos e ovinos e identificar os fatores de risco associados à infecção em animais criados em propriedades no Litoral/Zona da Mata e Agreste do Estado de Pernambuco.

\section{MATERIAL E MÉTODOS}

O trabalho consistiu de um estudo transversal para determinar a freqüência de caprinos e ovinos infectados pela Chlamydophila sp. e testar a relação entre o status sorológico e alguns possíveis fatores de risco.

O estudo foi realizado em propriedades do estado de Pernambuco que se situa a centro-leste da Região Nordeste do Brasil e está dividido em três grandes regiões geoeconômicas: Litoral/Zona da Mata, Agreste e Sertão. No Litoral/Zona da Mata, o clima é tropical úmido com temperaturas em torno dos $24^{\circ} \mathrm{C}$, índice pluviométrico entre 1.500 e $2.000 \mathrm{~mm}$ anuais e vegetação característica de mangue, no litoral, e Floresta Tropical, na Zona da Mata. No Agreste e Sertão, o clima é tropical semi-árido quente, com pluviosidade entre 650 e 1.000mm anuais (IBGE 2007).

Foram utilizados 290 animais, sendo 123 ovinos e 167 caprinos procedentes de 12 propriedades rurais localizadas na Zona da Mata de Pernambuco (municípios de Camaragibe, Jaboatão dos Guararapes, Igarassu, São Lourenço da Mata e Vicência) e Agreste (Brejo da Madre de Deus).

Nas 12 propriedades estudadas, o tamanho dos rebanhos variou de 14 a 360 animais, sendo que cinco propriedades eram de criação exclusivamente de caprinos, uma criava apenas ovinos e seis tinham ovinos e caprinos.

Foi realizada amostragem não-probabilística por conveniência (Thrusfield 2004), coletando-se amostras séricas para exames sorológicos de caprinos e ovinos para detecção de anticorpos anti- $C$. abortus.

Após a contenção dos animais e anti-sepsia com álcool iodado, as amostras de sangue foram colhidas mediante venopunção da jugular, utilizando-se agulhas hipodérmicas descartáveis calibre $40 \times 12 \mathrm{~mm}$, obtendo-se um volume de aproximadamente $10 \mathrm{~mL}$ que permaneceu em tubo de ensaio até completa retração do coágulo sangüíneo para a obtenção do soro que foi devidamente identificado e mantido a $-20^{\circ} \mathrm{C}$.

Para a pesquisa de anticorpos anti-Chlamydophila sp., foi empregada a microtécnica de Fixação de Complemento (OIE 2000), realizada no Laboratório de Doenças Bacterianas da Reprodução do Instituto Biológico de São Paulo. A reação foi realizada em microplacas utilizando-se soro teste nas diluições de 1:16 a 1:512. Utilizou-se como antígeno a cepa $\$ 26 / 3$ de $C$. abortus na diluição 1:50 e o complemento na diluição correspondente a duas unidades fixadoras de complemento. $O$ título de anticorpos foi considerado como a recíproca da maior diluição de soro que apresentou $50 \%$ de fixação do complemento. Amostras com título igual ou superior a 32 foram consideradas positivas e com título igual a 16 foram consideradas suspeitas.

Para o estudo dos fatores de risco associados à infecção, aplicou-se um questionário constituído de 34 perguntas fechadas, sendo sete relativas a informações sobre o criador, 21 sobre características gerais da propriedade como espécie, raça (pura ou mestiça), tipo de produção (leite ou carne), sistema de manejo (intensivo, semi-intensivo ou extensivo), aspectos sanitários (freqüência de limpeza das instalações, presença de assistência veterinária) e manejo reprodutivo (monta natural, monta controlada ou inseminação artificial) e seis sobre o status sanitário do rebanho (presença de doenças, especialmente problemas reprodutivos, além de pneumonia e conjuntivite). O questionário foi aplicado pelo mesmo entrevistador (Mainar et al. 1996).

A análise de fatores de risco foi efetuada em duas etapas: análise univariada e análise multivariada. $\mathrm{Na}$ análise univariada, cada variável independente foi cruzada com a variável dependente (condição sanitária do animal). As que apresentaram um valor de $p$ d" 0,15 pelo teste de qui-quadrado (Zar, 1999) foram selecionadas e oferecidas para a análise multivariada, utilizando-se a regressão logística múltipla (Hosmer \& Lemeshow, 2000), para a definição de um modelo que melhor identificasse os fatores de risco. O nível de significância adotado na análise múltipla foi de $5 \%$. O ajuste do modelo final foi verificado com o teste de Hosmer e Lemeshow e um p e" 0,05 indica que o modelo está ajustado. As análises foram realizadas com o programa SPSS for Windows versão 13.0.

\section{RESULTADOS E DISCUSSÃO}

A freqüência de animais soro-reagentes para Chlamydophila sp. foi de 10,3\% (30/290 animais), sendo 12,0\% (20/ 167) para caprinos e $8,1 \%(10 / 123)$ para ovinos. Observaram-se, ainda, $68(23,4 \%)$ animais suspeitos, sendo 48 $(28,7 \%)$ caprinos e 20 (16,3\%) ovinos (Quadro 1).

Os títulos observados neste estudo, de maneira geral, foram baixos. O maior título foi de 128 , em ovinos das 
Quadro 1. Recíproca dos títulos de anticorpos anti-Chlamydophila sp. em caprinos e ovinos procedentes da região do Litoral/Zona da Mata e Agreste de Pernambuco, 2006

\begin{tabular}{cccccccc}
\hline \multirow{2}{*}{ Espécie } & Total de & \multicolumn{5}{c}{ Título } & Total de \\
\cline { 3 - 7 } & amostras & Neg (\%) & $16(\%)$ & $32(\%)$ & $64(\%)$ & $128(\%)$ & positivos (\%) \\
\hline Caprino & 167 & $99(59,3)$ & $48(28,7)$ & $16(9,6)$ & $4(2,4)$ & - & $20(12,0)$ \\
Ovino & 123 & $93(75,6)$ & $20(16,3)$ & $6(4,9)$ & $1(0,8)$ & $3(2,4 \%)$ & $10(8,1)$ \\
Total & 290 & $192(66,2)$ & $68(23,4)$ & $22(7,6)$ & $5(1,7)$ & $3(1,0)$ & $30(10,3)$
\end{tabular}

propriedades um $(6,3 \%)$ e dez $(3,0 \%)$. Em caprinos, o maior título foi de 64 (3,0\%). No total, somente três $(1,0 \%)$ animais apresentaram título 128 , cinco $(1,7 \%)$ apresentaram título 64 e 22 (7,6\%), título 32 (Quadro 1).

De acordo com a OIE (2000), a Reação de Fixação de Complemento (RFC) pode detectar anticorpos de vacinação ou infecção natural. Como não é realizada a vacinação contra este agente na região estudada, os resultados indicam a presença de infecção, uma vez que o método parece refletir com acurácia o status do rebanho.

A resposta de anticorpos IgM específicos para clamídia sofre uma elevação uma semana após a infecção e, em seguida, cai drasticamente, permanecendo baixo até uma semana antes do parto ou aborto. A resposta de IgG, por outro lado, se mantém persistente por até dois anos e meio após a infecção (Papp et al. 1994). Também se observa um incremento de lgM, 2 a 3 semanas após a infecção intravaginal e uma semana após a infecção subcutânea. A resposta de IgG desenvolve-se mais lentamente, mas as ovelhas que apresentam distúrbios reprodutivos permanecem soropositivas após a reinfecção ou parto (Papp \& Shewen 1996).

Apesar de algumas propriedades terem relatado a ocorrência recente de abortamentos, não é possível associálos à infecção por esta bactéria, uma vez que foi realizada pesquisa do DNA deste agente em tecidos de fetos obtidos nestas propriedades e todas as amostras mostraram-se negativas.

Segundo Wilsmore et al. (1984), há uma boa correlação entre a presença de sinais clínicos de aborto enzoótico ovino e títulos maiores que 1:128. Igayara-Souza et al.
(2004) mostraram associação entre presença de amostras positivas na RFC e a ocorrência de abortamentos em rebanhos bovinos, em São Paulo, sugerindo a importância da C. abortus na etiologia de abortamentos nestes rebanhos e observaram, ainda, títulos elevados nos rebanhos com ocorrência de abortamentos.

A reação cruzada entre $C$. abortus e $C$. pecorum, assim como com outras bactérias Gram-negativas, pode resultar em alguns resultados falso-positivos com baixos títulos. Assim, títulos inferiores a 1:32 em indivíduos devem ser considerados inespecíficos para $C$. abortus (OIE 2000).

$\mathrm{O}$ alto percentual de animais suspeitos neste trabalho pode significar um número bem maior de animais positivos. Como não foi realizada a sorologia pareada, não foi possível confirmar o diagnóstico nesses animais.

A infecção é evidente principalmente durante a infecção ativa da placenta no último mês de gestação e logo após a fase de bacteremia que acompanha o aborto. Conseqüentemente, a colheita de soros pareados na época do aborto e três semanas depois, pode revelar uma elevação dos títulos de anticorpos na RFC, o que poderá servir de base para um diagnóstico retrospectivo (OIE 2000).

As propriedades apresentaram freqüência variando de $4,0 \%$ a $60,0 \%$ de animais positivos para Chlamydophila sp. Em $11(91,6 \%)$ das 12 propriedades, foi encontrado pelo menos um animal positivo (Quadro 2). Na propriedade 12 , não havia animais positivos, mas $5 / 24(20,8 \%)$ eram suspeitos. A menor ocorrência foi observada na propriedade $11(4,2 \%)$ e a maior, na propriedade $2(60,0 \%)$.

Quadro 2. Distribuição dos títulos de anticorpos anti-Chlamydophila sp. em caprinos e ovinos por propriedade do Litoral/Zona da Mata e Agreste de Pernambuco, 2006

\begin{tabular}{ccccccccc}
\hline \multirow{2}{*}{$\begin{array}{c}\text { Propri- } \\
\text { edade }\end{array}$} & Município & $\mathrm{N}$ & \multicolumn{5}{c}{ Título (\%) } & Total de \\
\cline { 5 - 7 } & & & Negativo & 16 & 32 & 64 & 128 & positivos \\
\hline 1 & Vicência & 16 & $13(81,3)$ & $1(6,3)$ & $1(6,3)$ & - & $1(6,3)$ & $2(12,6)$ \\
2 & Camaragibe & 10 & - & $4(40,0)$ & $4(40,0)$ & $2(20,0)$ & - & $6(60,0)$ \\
3 & Camaragibe & 10 & $5(50,0)$ & $4(40,0)$ & $1(10,0)$ & - & - & $1(10,0)$ \\
4 & Igarassu & 20 & $9(45,0)$ & $9(45,0)$ & $1(5,0)$ & $1(5,0)$ & - & $2(10,0)$ \\
5 & Camaragibe & 25 & $17(68,0)$ & $1(4,0)$ & $6(24,0)$ & $1(4,0)$ & - & $7(28,0)$ \\
6 & Camaragibe & 18 & $16(88,9)$ & $1(5,6)$ & $1(5,6)$ & - & - & $1(5,6)$ \\
7 & Camaragibe & 38 & $29(76,3)$ & $7(18,4)$ & $2(5,3)$ & - & - & $2(5,3)$ \\
8 & Camaragibe & 25 & $17(68,0)$ & $6(24,0)$ & $2(8,0)$ & - & - & $2(8,0)$ \\
9 & Camaragibe & 14 & $6(42,9)$ & $6(42,9)$ & $2(14,3)$ & - & - & $2(14,3)$ \\
10 & Brejo da Madre de Deus & 66 & $46(69,7)$ & $16(24,2)$ & $1(1,5)$ & $1(1,5)$ & $2(3,0)$ & $4(6,0)$ \\
11 & São Lourenço da Mata & 24 & $15(62,5)$ & $8(33,3)$ & $1(4,2)$ & - & - & $1(4,2)$ \\
12 & Jaboatão dos Guararapes & 24 & $19(79,2)$ & $5(20,8)$ & - & - & - & -
\end{tabular}


A presença de pelo menos um animal positivo em $91,6 \%$ das propriedades estudadas indica que existem vários focos da infecção que pode ser considerada amplamente disseminada na região estudada. No entanto, a freqüência de animais positivos (10,3\%) ainda é bem inferior àquela relatada em outros países como Espanha, 50,5\% (Mainar-Jaime et al., 1998), Estados Unidos, 23\% (Moeller 2001), Itália, 18 a 24\% (Chiocco et al. 1992) e Suíça, 19\% (Borel et al. 2004). Por outro lado, Masala et al. (2005) também relataram uma baixa soroprevalência de C. abortus em ovinos (4,8\%) e caprinos (5,8\%), na região da Sardenha, na Itália, onde consideraram que este agente tem menor importância como causa de aborto nestas espécies.

Piatti et al. (2006), trabalhando com soros de caprinos e ovinos procedentes dos Estados de São Paulo, Minas Gerais, Mato Grosso e Bahia, encontraram 12,0\% de positivos entre os caprinos, mas nenhum positivo entre os ovinos, pela Reação de Fixação do Complemento. Os percentuais de animais reagentes encontrados por estes autores foi muito semelhante ao observado no presente trabalho. Porém, ao contrário do que foi relatado por Piatti et al. (2006), em São Paulo, foram encontrados em ovinos $(8,1 \%)$ no Estado de Pernambuco, sendo este o pri- meiro registro da infecção por $C$. abortus em ovinos no Brasil e em caprinos no Estado de Pernambuco.

As propriedades 1, 3, 4, 11 e 12 haviam sido visitadas por solicitação dos criadores devido à ocorrência de abortamentos. Na propriedade 2, a freqüência de animais positivos foi alta, quatro $(40,0 \%)$ animais apresentaram título $1: 16$, quatro $(40,0 \%)$ apresentaram título $1: 32$ e dois $(20,0 \%)$, título 1:64. Contudo, não havia histórico de abortamento. O responsável pelos animais relatou a ocorrência de falhas reprodutivas no último ano, mas não de abortos e mortalidade neonatal.

A freqüência de caprinos positivos (12,0\%) foi superior à freqüência de ovinos $(8,1 \%)$ e a OR para caprinos foi de 1,54 , porém sem associação significativa $(p>0,05)$.

Nos Quadros 3 e 4 estão resumidas as variáveis analisadas e comparadas à soropositividade para Chlamydophila sp. em caprinos e ovinos, respectivamente. Para a espécie caprina, das oito variáveis estudadas, quatro apresentaram associação significativa $(p<0,05)$ pela análise univariada (Quadro 3). No entanto, somente duas (raça e manejo intensivo) foram confirmadas pela análise multivariada (Quadro 5). Por outro lado, para a espécie ovina não foram observadas associações significativas para os fatores de risco estudados (Quadro 4).

\begin{tabular}{|c|c|c|c|c|c|}
\hline Variável & № de animais & Freqüência (\%) & $\mathrm{OR}^{\mathrm{a}}$ & $\mathrm{IC}^{\mathrm{b}} 95 \%$ & $\mathrm{P}$ \\
\hline \multicolumn{6}{|l|}{ Raça Predominante } \\
\hline Pura & 44 & 31,8 & 9,10 & $2,91-29,62$ & $<0,001$ \\
\hline Mestiça & 123 & 4,9 & & & \\
\hline \multicolumn{6}{|l|}{ Sistema de Manejo } \\
\hline Intensivo & 86 & 19,8 & 6,41 & $1,65-29,14$ & 0,0014 \\
\hline Semi-intensivo & 81 & 3,7 & & & \\
\hline Extensivo & - & - & & & \\
\hline \multicolumn{6}{|l|}{ Tipo de Exploração } \\
\hline Leite & 59 & 20,3 & 3,19 & $1,12-9,26$ & 0,0141 \\
\hline Carne & 108 & 7,4 & & & \\
\hline \multicolumn{6}{|l|}{ Procedência dos animais } \\
\hline Mesmo município & 21 & - & N.A. & - & \\
\hline Municípios vizinhos & 65 & 13,8 & & & 0,3088 \\
\hline Outros Estados & 20 & 10,0 & & & \\
\hline Exposições e leilões & 61 & 14,8 & & & \\
\hline \multicolumn{6}{|l|}{ Limpeza das instalações } \\
\hline Diária & 51 & 9,8 & & - & 0,7455 \\
\hline Semanal & 55 & 14,5 & & & \\
\hline Mensal & 61 & 11,5 & & & \\
\hline \multicolumn{6}{|l|}{ Assistência Veterinária } \\
\hline Possui & 62 & 6,5 & 2,61 & $0,76-9,75$ & 0,0920 \\
\hline Não possui & 105 & 15,2 & & & \\
\hline \multicolumn{6}{|l|}{ Manejo Reprodutivo } \\
\hline Monta natural & 72 & 19,4 & & & 0,0342 \\
\hline Monta controlada & 83 & 6,0 & & & \\
\hline Inseminação Artificial & 12 & 8,3 & & & \\
\hline \multicolumn{6}{|l|}{ Compartilha reprodutor } \\
\hline Sim & 32 & 6,3 & 0,43 & $0,06-2,14$ & 0,2686 \\
\hline Não & 135 & 13,3 & & & \\
\hline
\end{tabular}


Mainar-Jaime et al. (1998), realizaram um estudo epidemiológico em criações de ovinos na Espanha e identificaram quatro fatores de risco associados à soroprevalência para clamydophila (exploração, proximidade entre as criações, política de substituição e freqüência de abortos no rebanho).

Para a variável raça, a freqüência de caprinos soropositivos foi de $31,8 \%$ em animais de raça pura e de $4,9 \%$ para os mestiços (Quadro 3), enquanto que a freqüência de ovinos de raças puras e mestiças foi, respectivamente, $6,6 \%$ e $12,5 \%$ (Quadro 4). Em caprinos, observou-se associação altamente significativa entre soropositividade e raça pura $(O R=9,10 ; p<0,0001)$. As raças nativas e exóticas foram estudadas por Mainar-Jaime et al. (1998), que encontraram OR de 1,43 para raças exóticas, mas este valor não foi estatisticamente significativo.

Em relação ao manejo, observou-se em caprinos uma associação significativa $(p<0,01)$ entre o sistema de manejo e a soropositividade para clamydophila. No sistema intensivo, a freqüência de animais soropositivos foi de $19,8 \%(\mathrm{OR}=6,41)$, enquanto que no semi-intensivo foi de $3,7 \%$ (Quadro 3). Em ovinos, a soropositividade para clamydophila foi nula para animais criados em regime intensivo, 6,3\% para aqueles de regime semi-intensivo e
$19,0 \%$ em regime extensivo, sem associação significativa $(p>0,05)$ (Quadro 4).

A freqüência de animais soropositivos foi de $20,3 \%$ em caprinos de leite $(\mathrm{OR}=3,19)$ e $7,4 \%$ em animais de carne, com associação significativa entre esta variável e a presença de anticorpos $(p<0,05)$, pela análise univariada, mas não confirmado pela regressão logística. A exploração de ovinos na região estudada visa principalmente a produção de carne e por isso não foi possível analisar a variável "tipo de exploração" nesta espécie.

A produção de leite em ovinos foi considerada um fator de risco por Mainar-Jaime et al. (1998), que relataram OR de 2,14. A variável produção de leite pode estar relacionada à raça e sistema de manejo, uma vez que na criação leiteira utiliza-se principalmente o sistema intensivo com animais de raças puras importadas e seus cruzamentos. Estes mesmos fatores por outro lado, poderiam influenciar a espécie, visto que se observou uma ocorrência maior da infecção em caprinos $(12,0 \%)$, do que em ovinos $(8,1 \%)$.

As diferenças entre raças também podem influenciar as diferenças na soroprevalência entre animais de produção de carne e de leite. Rebanhos leiteiros geralmente tem um maior número de animais de raças puras ou exóticas.

Quadro 4. Fatores de risco associados à infecção por Chlamydophila sp. para ovinos criados na região do Litoral/ Zona da Mata e Agreste de Pernambuco, 2006, estimados pelo teste do Qui-quadrado

\begin{tabular}{|c|c|c|c|c|c|}
\hline Variável & № de animais & Freqüência (\%) & $\mathrm{OR}^{\mathrm{a}}$ & $I^{b} 95 \%$ & $\mathrm{P}$ \\
\hline \multicolumn{6}{|l|}{ Raça Predominante } \\
\hline Pura/ exótica & 91 & 6,6 & 0,49 & $0,11-2,30$ & 0,2949 \\
\hline Mestiça/ nativa & 32 & 12,5 & & & \\
\hline \multicolumn{6}{|l|}{ Sistema de Manejo } \\
\hline Intensivo & 6 & 0 & N.A. ${ }^{c}$ & - & 0,1143 \\
\hline Semi-intensivo & 96 & 6,3 & & - & \\
\hline Extensivo & 21 & 19,0 & & & \\
\hline \multicolumn{6}{|l|}{ Tipo de Exploração } \\
\hline Carne & 123 & 7,4 & N.A. & - & - \\
\hline Leite & - & - & & & \\
\hline \multicolumn{6}{|l|}{ Procedência dos animais } \\
\hline Mesmo município & 3 & - & N.A. & - & 0,5372 \\
\hline Municípios vizinhos & 13 & 15,4 & & & \\
\hline Exposições e leilões & 107 & 7,5 & & & \\
\hline Outros Estados & - & & & & \\
\hline \multicolumn{6}{|l|}{ Limpeza das instalações } \\
\hline Diária & 70 & 7,1 & - & - & 0,6664 \\
\hline Semanal & 14 & 14,3 & & & \\
\hline Mensal & 39 & 7,7 & & & \\
\hline \multicolumn{6}{|l|}{ Assistência Veterinária } \\
\hline Possui & 103 & 7,8 & 0,76 & $0,13-5,73$ & 0,7391 \\
\hline Não possui & 20 & 10,0 & & & \\
\hline \multicolumn{6}{|l|}{ Manejo Reprodutivo } \\
\hline Monta natural & 42 & 9,5 & - & - & 0,9166 \\
\hline Monta controlada & 39 & 7,7 & & & \\
\hline Inseminação Artificial & 42 & 7,1 & & - & \\
\hline \multicolumn{6}{|l|}{ Compartilha reprodutor } \\
\hline Sim & 6 & - & 0,00 & $0,00-12,16$ & 0,4568 \\
\hline Não & 117 & 8,5 & & & \\
\hline
\end{tabular}

Pesq. Vet. Bras. 29(1):33-40, janeiro 2009 


\section{Quadro 5. Fatores de risco para Chlamydophilla sp. em ovinos e caprinos criados na região do Litoral/ Zona da Mata e Agreste do Estado de Pernambuco, 2006, estima- dos por regressão logística múltipla}

\begin{tabular}{lccc}
\hline Fatores de risco & Odds Ratio & IC 95 \% & $P$ \\
\hline Predominância de raça pura & 6,65 & $2,3019,27$ & $<0,001$ \\
Manejo intensivo & 4,18 & $1,12-15,64$ & 0,034
\end{tabular}

Teste de Hosmer e Lemeshow: $\chi^{2}=0,497 ; p=0,78$.

A associação significativa entre o manejo intensivo e a presença de infecção por esta bactéria em caprinos demonstra a importância do contato entre os animais para a transmissão do agente. Este fator também explicaria a maior freqüência de positividade em caprinos do que em ovinos, pois $51,5 \%$ dos caprinos eram criados em sistema intensivo contra apenas $4,9 \%$ de ovinos neste sistema.

Wehrend et al. (2005) observaram relação estatisticamente significativa $(p<0,001)$ entre a presença de anticorpos contra Chlamydophila sp. e o tipo de alojamento em rebanhos bovinos leiteiros estudados na Alemanha. Os animais mantidos soltos em estábulos apresentaram maior freqüência de positividade $(57,0 \%)$ que os animais que permaneciam amarrados $(35,0 \%)$. O maior contato entre os animais soltos poderia explicar essa maior freqüência, principalmente se considerar que a infecção fecal-oral é a mais importante via de transmissão.

Entre os caprinos examinados, $12,5 \%$ eram procedentes do mesmo município, 38,7\% eram de outros municípios, $11,9 \%$ eram de outros Estados e 36,9\% foram adquiridos em exposições. Não foram encontrados animais positivos no grupo de animais oriundos do mesmo município. A freqüência de animais soropositivos foi respectivamente de $13,8 \%, 10 \%$ e $14,8 \%$, sem associação significativa entre as variáveis (Quadro 3). Entre os ovinos, $2,5 \%$ eram procedentes de propriedades do mesmo município, $10,7 \%$ eram de municípios vizinhos e $86,9 \%$ foram adquiridos em leilões ou exposições oficiais. A freqüência observada foi de $15,4 \%$ para os animais adquiridos de municípios vizinhos e 7,5\% para animais comprados em leilões e exposições, não se observando associação significativa ( $p>0,05)$ (Quadro 4).

A política de substituição dos animais também foi estudada por Mainar-Jaime et al. (1998), em ovinos, onde observaram maior prevalência de soropositivos quando os animais eram adquiridos de rebanhos cujo histórico não era conhecido, porém esta variável não apresentou significância. Para bovinos de leite, também não foi encontrada associação entre a soroprevalência e a origem dos animais (Mainar-Jaime 2003).

Quanto à freqüência de limpeza das instalações, não foi observada associação significativa para nenhuma das duas espécies (Quadros 3 e 4). Em caprinos de propriedades com limpeza diária, semanal e mensal, respectivamente, a ocorrência foi de $9,8 \%, 14,5 \%$ e $11,5 \%$ de soro- reagentes, enquanto que para ovinos, a ocorrência foi de $7,1 \%, 14,3 \%$ e $7,7 \%$, respectivamente.

Os caprinos de propriedades com e sem assistência veterinária apresentaram freqüência respectivamente de 6,5 e $15,2 \%$, enquanto que em propriedades de ovinos observou-se 7,8 e $10,0 \%$ de soropositividade. Não se observou associação significativa para esta variável, $(p>0,05)$ para as duas espécies (Quadros 3 e 4 ).

Com relação ao manejo reprodutivo, em caprinos, a inseminação artificial era utilizada em 7,1\%, a monta controlada em $50,0 \%$ e a monta natural em $42,9 \%$. Observou-se associação significativa $(p<0,05)$ entre a infecção e o manejo reprodutivo (Quadro 3), que não foi confirmada pela análise multivariada. Nas propriedades onde se utilizava a monta natural, a freqüência de animais sororeagentes foi maior $(19,4 \%)$ quando comparada àquelas onde os animais eram submetidos à inseminação artificial $(8,3 \%)$ e monta controlada (6,0\%). O cálculo da OR pela análise de tendência linear foi 3,77, mas sem associação significativa .

Em ovinos, 34,4\% eram submetidos à inseminação artificial, $31,1 \%$ à monta controlada e $34,4 \%$ à monta natural. A freqüência de animais infectados foi respectivamente de 7,1\%, 7,9\% e 7,1\% e não se observou associação significativa (Quadro 4).

Apesar de não ter sido confirmado como fator de risco, o manejo reprodutivo é de importância na transmissão venérea em caprinos. A eliminação deste agente em excreções vaginais foi demonstrada no período periovulatório (Papp \& Shewen 1996) e no pré-parto (McEwen et al 1951). Por outro lado, a clamydophila já foi isolada do fluído seminal de carneiros (Bernstein \& Yaakobovitz 1990), touros (Storz et al. 1968, Gomes et al. 2001) e varrões (Teankum et al. 2006).

A transmissão venérea do carneiro infectado para oveIhas não infectadas foi demonstrada experimentalmente por Papp \& Shewen (1996). No entanto, embora biologicamente possível, acredita-se que esta forma de transmissão não contribua muito para a epidemiologia dos abortos em ovinos criados em sistemas onde há pouco contato entre o macho e a fêmea (Appleyard et al. 1985).

Neste estudo, observou-se que muitos caprinos são criados em sistema intensivo e, freqüentemente, sem separação por sexo. Isto favorece o maior contato entre machos e fêmeas e, conseqüentemente, a transmissão venérea pode contribuir consideravelmente para a disseminação do agente neste sistema.

Somente $4,1 \%$ dos ovinos e $19,6 \%$ dos caprinos eram procedentes de propriedades que compartilhavam reprodutores e a freqüência da infecção foi nula em ovinos e $6,3 \%$ em caprinos, sem associação significativa ( $p>0,05)$ (Quadros 3 e 4).

Este estudo analisou também o relato de algumas patologias no rebanho como repetição de cio, mortalidade neonatal e aborto.

Os caprinos procedentes de rebanhos com histórico de repetição de cio apresentaram freqüência de $11,1 \%$ 
contra $15,6 \%$ para animais de rebanhos sem histórico. Em ovinos, a freqüência foi, respectivamente, $7,5 \%$ e $11,8 \%$. Não houve associação significativa $(p>0,05)$ entre a infecção e este fator.

A mortalidade neonatal foi relatada em $74,4 \%$ dos caprinos e $75,4 \%$ dos ovinos. Nos grupos de caprinos com e sem histórico de mortalidade neonatal, a freqüência de soropositivos foi de, respectivamente, 9,6\% e 19,0\%, sem associação significativa. Nos ovinos a freqüência de soropositivos foi maior no grupo com histórico de mortalidade neonatal $(8,7 \%)$ do que no grupo sem histórico $(6,5 \%)$, porém, apesar da OR calculada ter sido de 1,38, não houve associação estatisticamente significativa.

O aborto foi relatado em $50,0 \%$ das amostras de ovinos e $76,2 \%$ de caprinos. Nos grupos de caprinos com e sem histórico de aborto, foram encontrados respectivamente $10,2 \%$ e $17,5 \%$ de soropositivos, enquanto que nos ovinos foram observados 8,1 e $8,2 \%$, respectivamente. Para nenhuma das duas espécies foi observada associação significativa entre a soropositividade e a ocorrência de aborto $(p>0,05)$.

Mainar-Jaime et al. (1998) descreveram associação significativa entra a freqüência de abortos e a soroprevalência em ovinos $(O R=2,40)$. Travnicek et al. (2003) também relataram diferenças na soroprevalência de $C$. abortus em rebanhos ovinos sadios $(13,9 \%)$ e com distúrbios reprodutivos $(45,8 \%)$.

No presente estudo, é possível que os abortos tenham sido subestimados, uma vez que seu registro dependeu da observação dos responsáveis. Além disso, conforme já observado por Leal et al. (1992), os produtores têm dificuldade em diagnosticar corretamente os abortos, freqüentemente confundidos com mortalidade perinatal.

Outra consideração importante é que $C$. abortus pode não ser uma causa importante de aborto na região estudada, ao contrário do que foi relatado em alguns países da Europa (Wilsmore \& Dawson 1986, Mainar-Jaime et al. 1998, Borel et al. 2004), onde este agente é a principal causa de aborto infeccioso em ovinos e caprinos. É possível que outros agentes infecciosos como Toxoplasma gondii, tenha maior participação na ocorrência de problemas reprodutivos na região estudada.

Muitos outros agentes infecciosos e parasitários podem estar envolvidos como causa de aborto em pequenos ruminantes. A Brucella sp é considerada uma das principais causas de aborto em ruminantes, mas em caprinos e ovinos ainda não é considerado importante (Silva \& Silva 1988). Além desta bactéria, Salmonella abortus ovis, o vírus de Border e o Toxoplasma gondii são considerados os principais agentes do abortamento em pequenos ruminantes (Pérez et al. 2003). Outros agentes ocorrem de forma esporádica e também já foram diagnosticados em casos de abortamento como Coxiella burnetii, Leptospira spp., Campylobacter sp., Listeria monocytogenes, Escherichia coli, Pseudomonas aeruginosa, Staphylococcus aureus e Streptococcus spp. (Chattopadhyay et al. 2001, Pérez et al. 2003, Masala et al. 2005, Szeredi et al. 2006).

\section{CONCLUSÃO}

Registra-se a primeira ocorrência de anticorpos anti-Chlamydophila sp. em ovinos no Brasil e em caprinos no estado de Pernambuco. A infecção por esta bactéria encontra-se disseminada nas criações de caprinos e ovinos da Zona da Mata e Agreste do Estado de Pernambuco. Medidas de controle devem ser implantadas nos criatórios estudados, enfocando principalmente os fatores de risco identificados neste estudo para reduzir a possibilidade de infecção por este agente.

\section{REFERÊNCIAS}

Appleyard W.T., Aitken I.D. \& Anderson I.E. 1985. Attempted venereal transmission of Chlamydia psittaci in sheep. Vet. Rec. 116:535-538.

Bernstein M.D. \& Yaakobovitz J. 1990. The identification and preventions of venereal transmission of Chlamydia psittaci in sheep. Israel J. Vet. Med. 45:192.

Borel N., Doherr M.G.O., Vretou E.O., Psarrou E., Thoma R. \& Pospischil A. 2004. Seroprevalence for ovine enzootic abortion in Switzerland. Prev. Vet. Med. 65:205-216.

Chattopadhyay U.K., Rashid M., Sur S.K. \& Pal D. 2001. The occurrence of campylobacteriosis in domestic animals and their handlers in and around Calcutta. J. Med. Microbiol. 50:933-934.

Chiocco D., Troiano P. \& Cavaliere N. 1992. Diffusione della chlamydiosi come cause di aborto in allevamenti ovi-caprini della Puglia e della Basilicata. Práxis Veterinária, Milano, 13:21-22.

Freitas J.A. \& Machado R.D. 1988. Isolamento de Chlamydia psittaci em búfalos abatidos para consumo em Belém, Pará. Pesq. Vet. Bras. 8:43-50.

Gomes M.J.P.O., Wald V.B.O., Machado R.D.O. \& Silveira M.C. 2001. Isolamento de Chlamydia psittaci em touros com vesiculite seminal, no Rio Grande do Sul. Hora Vet. 119:43-46.

Hosmer D.W. \& Lemeshow S. 2000. Applied logistic regression. John Wiley \& Sons, New York. 375p.

IBGE 2007. Instituto Brasileiro de Geografia e Estatística. http:// www.sidra.ibge.gov.br. Acesso em 10 de julho de 2006.

Igayara-Souza C.A., Genovez M.E., Ferreira F., Paulin L.M., Sacarcelli E., Cardoso M.V. \& Turilli C. 2004. Ocorrência de anticorpos antiChlamydophila em bovinos e avaliação de possível relação com distúrbios reprodutivos em São Paulo, Brasil. Revta Bras. Reprod. Anim. 28:28-33.

Leal T.M.O., Quirin R.O. \& Guimarães Filho C. 1992. Estudo do aborto caprino sob condições extensivas de criação no semi-árido baiano. Pesquisa em Andamento 69, Embrapa-CPATSA, Sobral, CE. 3p.

Mainar R.C., De La Cruz C., Asencio A., Dominguez L. \& Boland J.A.V. 1996. Prevalence PF agglutinating antibodies to Toxoplama gondii in small ruminants of the Madri Region, Spain, and identification of factors influencing seropositivy by multivariate analisys. Vet. Res. Commun. 20:153-159.

Mainar-Jaime R.C., Cruz C. \& Boland J.A.V. 1998. Epidemiologic study of clamydial infection in sheep animal farms in Madrid, Spain. Small Ruminant Res. 28:131-138.

Mainar-Jaime R.C. 2003. Clamidiosis bovina: estudio seroepidemiológico y relación com los abortos. Albéitar 67:30-32.

Masala G., Porcu R., Sanna G. Tanda A. \& Tola S. 2005. Role of Chlamydophila abortus in ovine and caprine abortion in Sardinia, Italy. Vet. Res. Commun. 29:117-123.

McEwen A.D., Littlejohn A.I. \& Foggie A. 1951. Enzootic Abortion in ewes: Some aspects of infection and resistance. Vet. Rec. 63:489492.

Moeller R.B.J.R. 2001. Causes of caprine abortion: diagnostic 
assessment of 211 cases (1991-1998). J. Vet. Diagn. Invest. 13:265270.

Nieuwhof G.J. \& Bishop S.C. 2005. Costs of major endemic diseases of sheep in Great Britain and the potential benefits of reduction in disease impact. Anim. Sci. 81:23-29.

OIE 2000. Enzootic abortion of ewes (ovine chlamydiosis). Manual of Standards for Diagnostic Tests and Vaccines. 4th ed. Office International des Epizooties. Disponível em http://www.oie.int/eng/normes/ mmanual. Acesso em: 11 de outubro de 2006.

Papp J.R., Shewen P.E. \& Gartley C.J. 1994. Abortion and subsequent excretion of Chlamydiae from the reproductive tract of sheep during estrus. Infect. Immun. 62:3786-3792.

Papp J.R. \& Shewen P.E. 1996. Pregnancy failure following vaginal infection of sheep with Chlamydia psittaci prior to breeding. Infect. Immun. 64:1116-1125.

Papp J.R. \& Shewen P.E. 1997. Chlamydia psittaci infection in sheep: a paradigm for human reproductive tract infection. J. Reprod. Immunol. 34:185-202.

Pérez A.L.G., Moreno B. \& Aduriz G. 2003. Necropsia y toma de muestras de abortos ovinos. Revta Ovis, Tratado de Patologia y Produccion Ovina 86:65-76.

Piatti R.M., Scarcelli E.P. \& Genovez M.E. 2006. Pesquisa de anticorpos anti-Chlamydophila em caprinos e ovinos. Biológico, São Paulo, 68:138-140.

Rodolakis A. 2001. Caprine Chlamydiosis. In: Tempesta M. Recent Advances in Goat Diseases. International Veterinary Information Service, Ithaca. Disponível em: http://www.ivis.org/advances/ Disease_Tempesta/rodolakis_chlamydiosis/chapter_frm.asp? LA=1. Acesso em: 15 agosto de 2004.

Romijn P.C. \& Liberal M.H.T. 1990. Cultivo de Chlamydia em diferentes sistemas celulares: um estudo comparativo. Pesq. Agropec. Bras. 25:15-18.
Silva M.U.D. \& Silva E.D.F. 1988. Possíveis causas de aborto em caprinos: diagnóstico, tratamento, profilaxia. Comunicado Técnico 12, Embrapa-CPATSA, Sobral, CE. 11p.

Storz J., Carrol E.J., Ball L. \& Faulkner L.C. 1968. Isolation of a psittacosis agent (Chlamydia) from semen and epididymis of Bulls with seminal vesiculitis syndrome. Am. J. Vet. Res. 29:549-555.

Szeredi L., Jánosi S., Tenke M., Tekes L., Bozsó M., Deim Z. \& Molnár T. 2006. Epidemiological and pathological study on the causes of abortion in sheep and goats in Hungary (1998-2005). Acta Vet. Hung. 54:503-515.

Teankum K., Pospischil A., Janett F., Burgi E., Brugnera E., Hoelzle K., Polkinghorne A., Weilenmann R., Zimmermann D.R. \& Borel N. 2006. Detection of Chlamydiae in boar semen and genital tracts. Vet. Microbiol. 116:149-157.

Thrusfield M.V. 2004. Epidemiologia Veterinária. $2^{\mathrm{a}}$ ed. Roca, São Paulo. $556 \mathrm{p}$.

Travnicek M., Kovacova D., Bhide M.R., Zubricky P. \& Cislakova L. 2003. Detection of IgG antibodies against Clamydophila abortus in sheep with reproductive disorders. Acta Vet., Brno, 72:95-99.

Wehrend A., Failing K., Hauser B., Jäger C. \& Bostedt H. 2005. Production, reproductive and metabolic factors associated with chlamydial seropositivity and reproductive tract antigens in dairy herds with fertility disorders. Theriogenology 63:923-930.

Wilsmore A.J., Parsons V. \& Dawson M. 1984. Experiments to demonstrate routes of transmission of ovine enzootic abortion. Brit. Vet. J. 140:380-391.

Wilsmore A.J. \& Dawson M. 1986. Chlamidial diseases of ruminant in Britain, p.13-16. In: Aitken D. (Ed.), Agriculture: Chlamydial diseases of ruminants. Proc. Commission. European Communities Seminar, Brussels.

Zar J.H. 1995. Biostatistical Analysis. 4th ed. Prentice Hall, Upper Saddle River, 663p. 